\title{
IbM MESIN PENGOLAH SAMPAH RUMAH TANGGA UNTUK MENUNJANG PROGRAM PEMBANGUNAN DI BIDANG KEBERSIHAN DI KOTA BENGKULU
}

\section{IbM; HOUSEHOLD WASTE PROCESSING MACHINE FOR SUPPORTING THE DEVELOPMENT PROGRAM OF CLEANLINESS IN BENGKULU CITY}

\author{
Oleh: \\ Ahmad Fauzan Suryono ${ }^{1)}$, Afdhal Kurniawan Mainil ${ }^{1)}$, dan Gusta Gunawan ${ }^{2)}$ \\ ${ }^{1)}$ Program Studi Teknik Mesin, Fakultas Teknik, Universitas Bengkulu. \\ ${ }^{2)}$ Program Studi Teknik Sipil, Fakultas Teknik, Universitas Bengkulu. \\ Email: ahmeedm2k@gmail.com, afdhal km@yahoo.com
}

\begin{abstract}
The aim of this community service is to improve the environment and public health in the city of Bengkulu, and the success of the human development index in the health sector. While the goal in particular is the amount of waste in the landfill can be significantly reduced over time so that the cleanliness of the environment and health can be realized, can boost the economic value of the plastic waste from households because it can be sold to a factory producing plastic pellets and machinery This can help people who are interested in waste processing technology to become entrepreneurs plastic pellets. This activity lasted for ten months in cooperation with two partners, namely the Parks Department and Sanitation of Bengkulu and CV Terang Bulan engaged in the sale of plastic waste. In implementing this program assisted with the research team of students to design and create a municipal waste processing machine a plastic which is more practical with affordable production costs for society. On completion of this machine in addition to the stages involves students will also involve CV. Terang Bulan as a partner in business who have started this garbage. The partners are expected to play an active role in providing fill-enter on the specifications desired by the user. After making machines is completed then it is disseminated to the public that waste management is important and profitable economically.
\end{abstract}

Keywords: Waste Processing Machines, Seeds plastic, household waste

\section{PENDAHULUAN}

Pertambahan jumlah penduduk menyebabkan volume sampah yang dihasilkan dari aktivitas masyarakat Kota Bengkulu juga meningkat. Untuk mengatasi masalah tersebut maka upaya yang dapat dilakukan adalah mengolah sampah rumah tangga baik jenis sampah sayuran maupun sampah plastik menjadi produk yang bisa bermanfaat bagi masyarakat sendiri. Tujuannya adalah untuk mengurangi volume sampah yang ada di Kota Bengkulu. 
Tabel 1. Timbunan Sampah Kota Bengkulu

\begin{tabular}{lc}
\hline \multicolumn{1}{c}{ Sumber Penghasil Sampah } & Unit (ton/hari) \\
\hline Pemukiman & 2,4 \\
Pasar & 0,8 \\
Perkantoran & 0,4 \\
Pertokoan & 0,4 \\
Hotel & 0,05 \\
Industri & 0,2 \\
Penyapuan Jalan dan Saluran & 0,2 \\
\hline Total & $\mathbf{4 , 4 5}$ \\
\hline
\end{tabular}

Sumber: Dinas Pertamanan dan Kebersihan, 2010

Upaya yang dilakukan oleh pemerintah Kota Bengkulu dalam penanganan sampah tersebut diatas adalah mengerahkan karyawan Dinas Kebersihan untuk mengumpulkan sampah rumah tangga tersebut dengan sepeda motor atau gerobak untuk di tumpuk ke TPS-TPS yang ada. Dari TPS tersebut sampah diangkut dengan truk ke TPA Air Sebakul.

Jumlah sampah semakin hari semakin meningkat maka dikwatirkan kapasitas TPA yang tersedia di Air Sebakul akan semakin berkurang. Oleh karena itu, jika pemerintah Kota Bengkulu masih menerapkan sistem sampah dengan pengelolaan konvensional seperti saat ini maka pada suatu saat akan terjadi gunung sampah di TPA Air Sebakul. Lama kelamaan di kwatirkan gunung sampah tersebut akan menjadi persoalan yang serius dan sulit untuk diselesaikan.

Undang-Undang RI No. 18 Tahun 2008 tentang Pengelolaan Sampah (Kemenenterian Hukum dan HAM, 2008) dan Peraturan Pemerintah RI No.81 tahun 2012 tentang Pengelolaan Sampah Rumah Tangga dan Sampah Sejenis Sampah Rumah Tangga (Kemenenterian Hukum dan HAM, 2012) mengamanatkan kepada pemerintah dan masyarakat untuk mengelola sampah dengan cara mengurangi volume sampah dari waktu ke waktu.

Permasalahan yang teridentifikasi pada saat ini berdasarkan analisis situasi diatas adalah kapasitas TPS dan TPA semakin lama semakin berkurang; teknologi pengolahan sampah masih rendah; sistem pengolahan sampah di TPA menimbulkan polusi udara dan bau yang tidak sedap; dan manajemen pengolahan sampah belum dilakukan secara Mekanisasi sehingga sulit untuk mengurangi volume sampah di TPA Air Sebakul.

Tujuan umum dari kegiatan ini adalah untuk meningkatkan kesehatan lingkungan dan masyarakat di Kota Bengkulu untuk mensukseskan Indek Pembangunan Manusia di Bidang Kesehatan. Tujuan rinci dari kegiatan ini adalah membuat mesin yang mampu mengelola sampah rumah tangga jenis plastik menjadi barang setengah jadi sehingga meningkatkan nilai ekonomi dari sampah plastik tersebut dan di transfer kepada masyarakat dan mitra kerjasama. Sementara manfaat dari kegiatan ini adalah sejumlah sampah yang ada di TPA dapat dikurangi secara signifikan dari waktu ke waktu sehingga 
kebersihan lingkungan dan kesehatan bisa terwujud; dapat menigkatkan nilai ekonomi dari Sampah plastik yang berasal dari rumah tangga karena bisa dijual ke pabrik penghasil biji plastik; mesin ini bisa membantu masyarakat yang berminat dalam teknologi pengolahan sampah untuk menjadi pengusaha biji plastik. Selanjutnya, manfaat bagi Pemerintah Daerah Kota Bengkulu adalah lingkungan menjadi bersih sehingga bisa membantu Pemda untuk meningkatkan kebersihan kota dan keindahan lingkungan, akan menciptakan lapangan pekerjaan sehingga mengurangi pengangguran (Departemen Pekerjaan Umum, 2007).

\section{METODE PENGABDIAN}

Teknik operasional pengolahan sampah perkotaan yang dilaksanakan secara terpadu dapat dilihat pada gambar berikut.

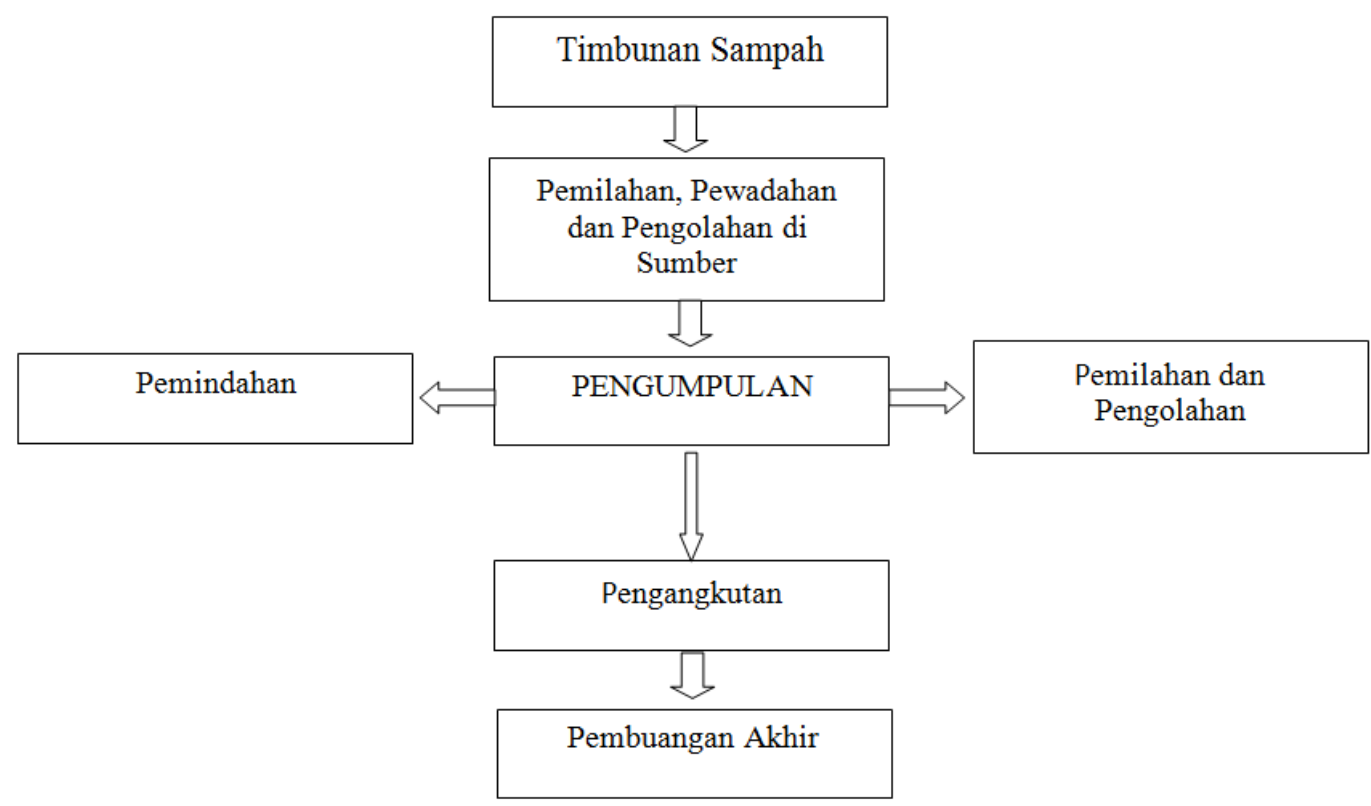

Gambar 1. Teknik Operasional Pengolahan Sampah (BSNI, 2002)

Teknik-teknik pengolahan sampah dapat berupa pengomposan dan daur ulang. Pengomposan dilakukan pada sampah organik sehingga bisa menghasilkan pupuk kompos yang sangat bermanfaat untuk pertanian. Sedangkan untuk sampah non organik terutama sampah jenis plastik maka upaya yang dilakukan adalah dengan mendaur ulang sampah plastik tersebut menjadi biji plastik. Untuk melakukan daur ulang plastik ini menjadi biji plastik maka dibutuhkan mesin pengolah sampah yaitu genset untuk sumber power; mesin pencacah sampah; mesin pengolah sampah menjadi biji plastik. Pada pengabdian ini yang akan dilakukan adalah pembuatan mesin pencacah sampah plastik sehingga bisa meningkatkan nilai ekonomi sampah plastik karena bisa dijual ke pengolah sampah biji plastik. 


\section{HASIL DAN PEMBAHASAN}

\section{Perancangan dan Proses Manufaktur}

Gambaran desain peralatan yang dibuat adalah seperti gambar berikut:
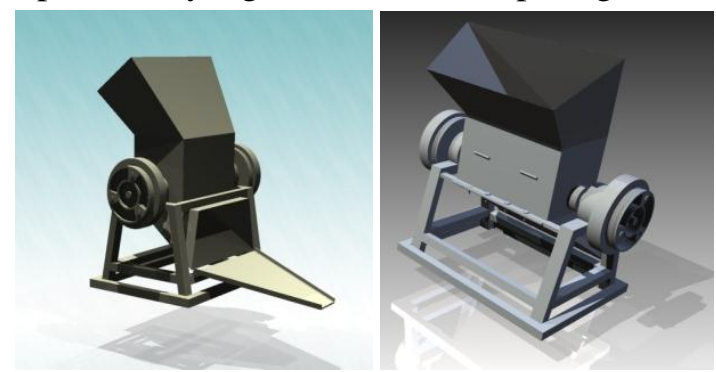

Gambar 2. Gambar Desain Peralatan

Proses manufaktur yang telah dilakukan dalam kegiatan pengabdian ini adalah sebagai berikut:

1. Pekerjaan Box Penampung Plastik dan Rangka Dudukan Mesin

Bak ini berfungsi untuk menampung plastik-plastik seperti botol-botol yang akan digiling juga berfungsi sebagai saluran masuk. Bak ini terbuat dari plat baja yang dilas dengan las listrik sehingga membentuk kotak atau box. Model bak atau saluran masuk yang akan dibuat adalah seperti gambar berikut:

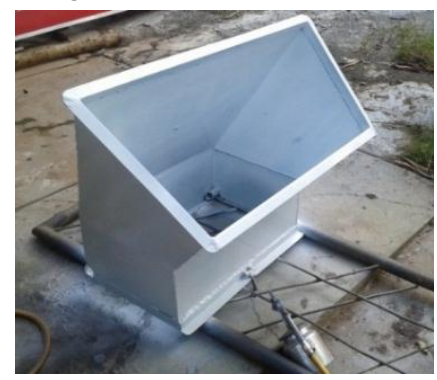

Gambar 3. Model Bak

Rangka dudukan mesin terbuat dari baja tipe L dan I. Desain dari rangka baja disesuaikan dengan fungsinya yaitu untuk dudukan mesin dan dudukan pondasi sehingga akan memperkokoh mesin dan mengurangi getaran yang terjadi selama proses berlangsung. Gambar rangka yang dilakukan proses manufakturnya adalah sebagai berikut:

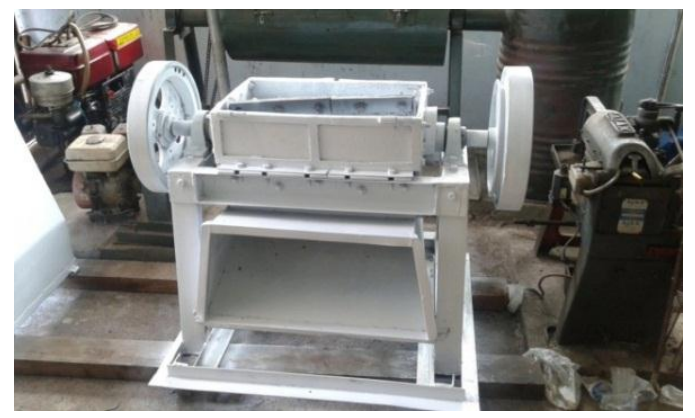

Gambar 4. Gambar Rangka 
Rangka tersebut sebagian akan dicor ke beton sehingga ketika mesin crusher dihidupkan, rangka baja tersebut harus tahan dan mampu menahan gaya-gaya yang timbul akibat getaran mesin.

\section{Pemasangan Roda Pemutar Pisau}

Roda ini terbuat dari bahan baja yang berbentuk lingkaran dan ditengah-tengahnya ada alur untuk pemasangan belt atau tali. Gunanya adalah sebagai alat untuk memutar pisau dengana arah putaran melingkar. Proses pembuatan roda ini adalah memalui proses pengecoran. Dalam pembuatan alat ini roda pemutar pisau tidak dibuat secara langsung tetapi dipesan dan hanya dilakukan nproses perakitan dengan komponen lainnya. Bentuk pisau pemotong yang telah dirakit dapat dilihat pada Gambar 5.

\section{Pembuatan Mata Pisau untuk Penghancur Sampah}

Mata pisau ini terbuat dari bahan besi yang kuat dan dibubut lalu dibentuk sedemikian rupa (Gambar 5). Mata potong pisau membentuk sudut sebesar 10 derjat dari garis sumbu poros, ini berfungsi agar daya pemotongan dari mesin pemotong plastik lebih kecil.

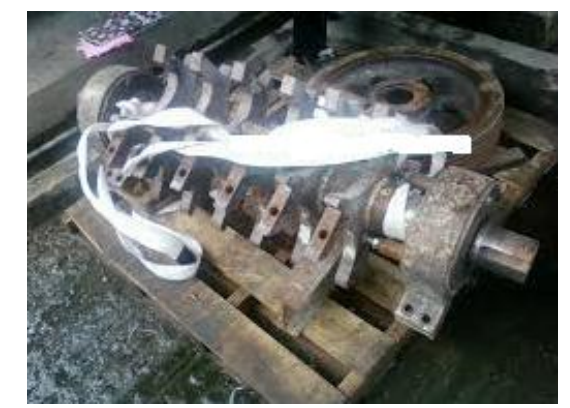

Gambar 5. Mata Pisau Alat Pencacah

\section{Perakitan Komponen}

Tahap selanjutnya yang akan dilakukan adalah melakukan perakitan dari semua komponen mesin yang ada. Kemudian akan dicoba untuk di-running dengan material sampah lalu dianalisis kinerjanya.

Hasil akhir perancangan:

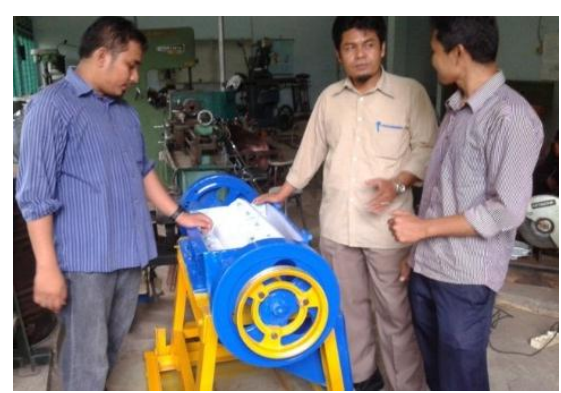


Gambar 6. Hasil Akhir Alat Rancang

\section{Kegiatan Pelatihan}

Sebelum dilakukan penyerahan peralatan kepada mitra terlebih dahulu mitra dan beberapa karyawannya diundang ke laboratorium Produksi teknik mesin untuk melakukan uji coba peraltana. Pelatihan penggunaan peralatan telah dilaksanakan di Laboratorium Produksi Prodi Teknik Mesin Universitas Bengkulu. Pelatihan ini diikuti oleh mitra yaitu dari CV Terang Bulan dan beberapa mahasiswa Teknik. Dalam Pelatihan ini diperkenalkan SOP penggunaan alat sekaligus sebagai uji coba peralatan yang telah dibuat. Berikut beberapa dokumentasi suasana kegiatan pengujian peralatan pengolah sampah.

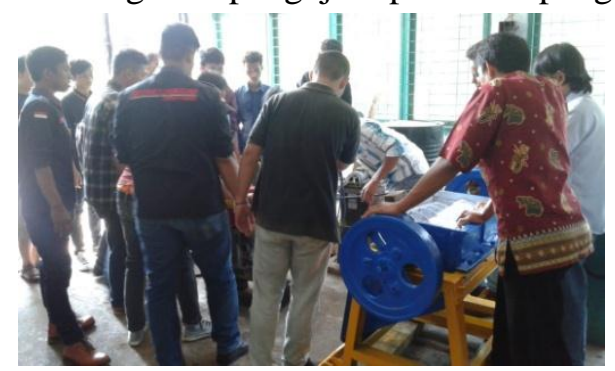

Gambar 7. Kegiatan Pengujian Alat

Prosedur penggunaan alat pencacah sampah plastik yaitu dengan memisahkan antara sampah plastik dengan sampah lainnya, pasangkan peralatan transmisi daya dari pully mesin ke pully motor, hidupkan motor diesel yang berfungsi sebagai motor penggerak mesin, setelah motor berjalan berputar secara stabil masukan sampah plastik ke dalam hoper dan langsung ditutup supaya tidak berterbangan, memasukkan sampah plastik ke dalam hoper dilakukan secara simultan dan perkirakan isi hoper jangan terlalu kosong atau padat dengan sampah plastik. Apabila agak susah keluarnya dan sampahnya menyangkut dibagian bawah selama proses bisa juga dialirkan air ke dalam hoper, tampung serpihan plastik pada bagian keluar mesin.

Dari hasil pengujian yang dilakukan pada alat pengolah sampah ini dapat dihasilkan produk cacahan plastik dengan ukuran bervariasi antara $3 \mathrm{~mm}$ sampai $2 \mathrm{~cm}$. Sedangakan kapasitas alat ini adalah berkisar anatar 50 - $70 \mathrm{~kg} / \mathrm{j}$ am tergantung kepada ketebalan plastis yang dicacah.

\section{Penyerahan Peralatan}

Setelah proses pengerjaan dan pelatihan penggunaan peralatan kepada mitra CV Terang Bulan. Kegiatan selanjutnya adalah penyerahan peraltan kepada mitra. Mitra CV Terang Bulan merupakan perusahaan usaha kecil menengah yang bergerak dalam jual beli barang bekas yang salah satunya adalah barang bekas plastik. 


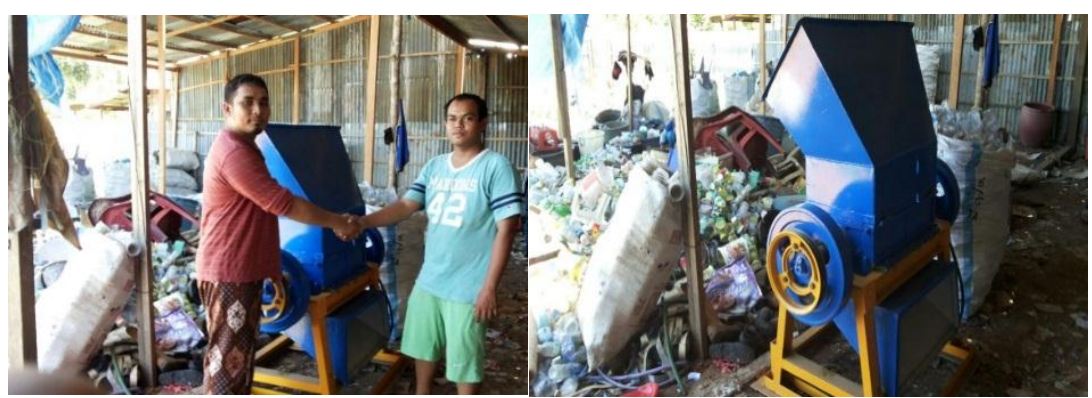

Gambar 8. Penyerahan Alat ke Mitra

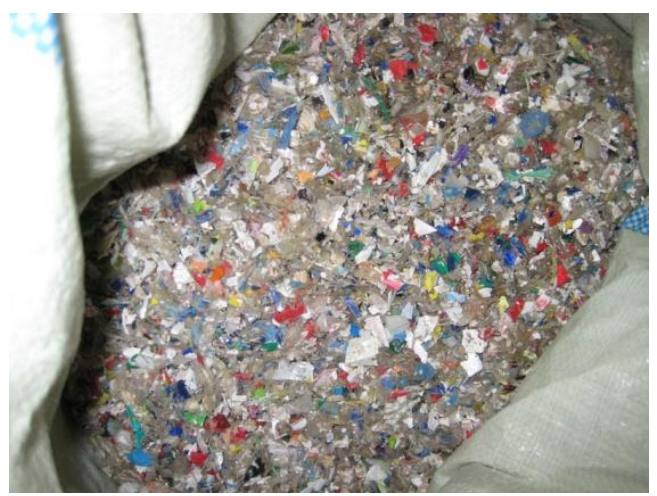

Gambar 9. Hasil Sampah Plastik yang telah Dicacah

\section{KESIMPULAN DAN SARAN}

\section{Kesimpulan}

Dari hasil kegiatan pengabdian masyarakat ini telah dihasilkan alat pengolah sampah plastik dengan spesifikasi sebagai berikut:

Tabel 2. Spesifikasi Hasil Olahan Plastik

\begin{tabular}{cll}
\hline No & \multicolumn{1}{c}{ Spesifikasi } & \multicolumn{1}{c}{ Ukuran } \\
\hline 1 & Dimensi mesin & \\
& Tinggi & $1,37 \mathrm{~m}$ \\
& Lebar & $1,25 \mathrm{~m}$ \\
2 & Jumlah blade(pisau) & 5 buah \\
3 & Penggerak & Motor Diesel (10,5 PS) \\
4 & Kapasitas & $50-70 \mathrm{~kg} / \mathrm{jam}$ \\
5 & Ukuran serpihan & $3 \mathrm{~mm}-2 \mathrm{~cm}$ \\
\hline
\end{tabular}

Penggunaan mesin pengolah sampah ini dapat meningkatkan produktivitas dari mitra dengan meningkatnya nilai tambah dari sampah plastik yang selama ini dijual hanya dalam bentuk sampah belum olah. Pengolahan sampah plastik menjadi bentuk yang ukurannya lebih kecil akan menghemat biaya pengiriman sampah plastik ke tempat 
pengolahan karena volumenya lebih kecil. Dengan adanya pegolahan sampah ini maka sampah-sampah plastik yang selama ini menjadi masalah kebersihan di Kota Bengkulu lambat laut dapt berkurang karena telah bernilai ekonomis.

\section{Saran}

Dari kegiatan pengabdian masyarakat di bidang IPTEKS bagi masyarakat ini diharapakan ke depannya terus berlanjut. Selain itu pengolahan sampah plastik ini tidak berhenti pada masalah pencacahan saja tetapi perlu ditingkatkan menjadi pengolahan biji plastik. Kemudian disarankan juga kepada Pemerintah Daerah untuk membuat tempat pengolahan langsung sampah plastik di Kota Bengkulu sehingga biaya transportasinya bisa ditekan dan lebih bernilai ekonomis bagi usaha-usaha pengolahan sampah.

\section{DAFTAR PUSTAKA}

BSNI, 2002, Tata Cara Teknik Operasional Pengelolaan Sampah Perkotaan, Badan Sertifikasi Nasional, Jakarta.

Departemen Pekerjaan Umum, 2007, Kisah Sukses Pengelolaan Persampahan di Berbagai Wilayah Indonesia, Jakarta.

Dinas Pertamanan dan Kebersihan, 2010, Bengkulu Master Plan Persampahan Kota Bengkulu.

Kemenenterian Hukum dan HAM, 2008, Undang-Undang RI No. 18 Tahun 2008 tentang Pengelolaan Sampah, Jakarta.

Kemenentrian Hukum dan HAM, 2012, Peraturan Pemerintah RI No. 81 Tahun 2012 tentang Pengelolaan Sampah Rumah Tangga dan Sampah Sejenis Sampah Rumah Tangga, Jakarta. 